\title{
Smartphone Controlled Fingerprint Door Look System (SCFDLS)
}

\author{
Ponmalar $\mathrm{A}^{\mathrm{a}, 1}$, Anand $\mathrm{J}^{\mathrm{b}}$, Dharshini $\mathrm{S}^{\mathrm{c}}$, Aishwariya $\mathrm{K}^{\mathrm{c}}$, Mahalakshmi $\mathrm{S}^{\mathrm{c}}$ and \\ Abinaya $\mathrm{S}^{\mathrm{c}}$ \\ a Assistant Professor, Sri Sai Ram Institute of Technology, Chennai \\ ${ }^{\mathrm{b}}$ Associate Professor, KCG College of Technology, Chennai \\ c Students, Sri Sai Ram Institute of Technology, Chennai
}

\begin{abstract}
Currently, the entire globe is infected with COVID 19, and everyone is doing everything they can do to avoid contracting this serious sickness by adhering to social segregation, wearing coverings, using credit-only exchanges, and refraining from contacting anything to prevent the spread of germs. With the advancement of technology, traditional locks are becoming relics of the past, while new biometric-based locks and Radio Frequency Identification (RFID)-based locks are becoming increasingly in common. The unique finger impression based locks, as well as participation record-keeping devices, are used in the vast majority of offices and universities, however due to the pandemic, it is no longer appropriate to do so. As a result, the proposed system use a solenoid lock to make the door lock. Aside from the equipment, a mobile application is used to inspect and double-check the finger impression and send the confirmation, as well as an id, to Arduino through Bluetooth. The entry way lock will be bolted and opened using the smartphone fingerprint sensor.
\end{abstract}

Keywords. Arduino, Bluetooth, Fingerprint, Solenoid Lock, Android Application

\section{Introduction}

This paper focused on the importance to have home security in the current situation. Every activity can be completed remotely in a modern home with many facilities and technology accessibility. Because burglaries and thefts are becoming more common these days, new home automation systems help to keep homes safe. These depict incorporates with technology plays a critical part in maintaining and improving the security of one's assets. As a result, the project's concept is to use Bluetooth technology in a tiny region of the most useful position, the door lock. This project shows a prototype of a smart door lock that can be used to improve the door's security. This project will employ Bluetooth characteristics in the mobile phone application to open the door automatically, allowing your phone to sync directly with the lock. It looks for the user and when it detects their presence, it immediately unlocks the door without the need to reach for the phone. There is also an Android app that may be used to control the door lock. It will detect the

\footnotetext{
${ }^{1}$ Ponmalar A, Sri Sai Ram Institute of Technology, Chennai, India.

E-mail: ponmalar.ragupathi@gmail.com
} 
person automatically. The door will open after a set amount of time has passed, and it will automatically close after that period has passed. In wireless houses, a safety answer primarily based totally on Internet of Things (IoT) and the HC-05 Bluetooth module is interfaced with an Arduino UNO that connects to the phone's Bluetooth. Each user's login credentials are stored in the Firebase database, that is a cloud-hosted database. Users can get right of entry to the door lock after their credentials had been established with the database over the net the use of clever gadgets which includes cellular telephones which have the app mounted and linked with the lock via Bluetooth with the aid of using transmitting signals.

\section{Literature Survey}

Few related articles are studied and the inference on the same is discussed below. Sriskanthan et al. [1] discussed numerous methods on sophisticated technology that can be taken. home automation is one of revolutionary technology nowadays toward realizing home automation, home appliance is made as easy as possible to be controlled by user several work of controlling home appliance has been done, such as door lock and unlock via smartphone door lock system. A home automation system using android application is designed and implemented [2]. Toschi et. al., discussed the creation of a mobile application and the integration of home automation [3]. AI-Ali, et. al. discussed a wireless technology-based home automation, several ways are used, such as a solenoid lock device [4]. A finger vein based security system is explained and implemented in [5]. Savita discussed about the Bluetooth Module (HC-05) [6], Shanthini et al. discussed about Buzzer [7], Arduino UNO, android application, M. Udin Harun Al Rasyid discussed on the database [8]. Cekada et al. have similar situations can be found at schools and universities. University students are increasingly technologically literate in today's world [9]. As a result, their focus in their environment and manual-primarily based totally sports are step by step declining. The aim of this venture is to apply Bluetooth generation with an Android platform [10]. Home automation is the begin of the usage of domestic generation to enhance human being's lives through supplying offerings along with multimedia amusement and strength efficiency. To placed it some other way, domestic automation specializes in the adaption of virtual gadgets to offer customers with real consolation whilst additionally preserving terrific security [11]. According to reports, a standard home automation system in prior years included a control digital device for heating and shading [12]. All of these features are included in the advantages of a home automation system. Security, illumination, electricity, weather control, irrigation, and entertain shows are all areas where a home automation system can be used, and the world is becoming more updated with the entertainment system over time [13]. An eemergency management system for medical application is used using microcontroller and a wireless communication technology [14]. Also a microcontroller based irrigation system application is used a mathematical system [15]. A security based door automation using infrared sensors and an authenticated users based on voice command [16]. A smart calendar device using Raspberry Pi is discussed in [17]. Sensor based embedded devices are implemented for healthcare application [18], stress detection [19], and smart monitoring device [20]. 


\section{Proposed System}

\subsection{Functions of Proposed Design}

The number one aim of this look at is to enhance the door locking system's security. The cautioned system's hardware and software program necessities are proven in discern 1 . The cell tool could be sending the sign thru Bluetooth to the Arduino circuit that acts as the relationship among the smartphones, and the Solenoid after the right authentication is furnished the use of the database. The usage of Bluetooth on cell phones allows for easier access while also providing greater security than a traditional key. Table 1 list the

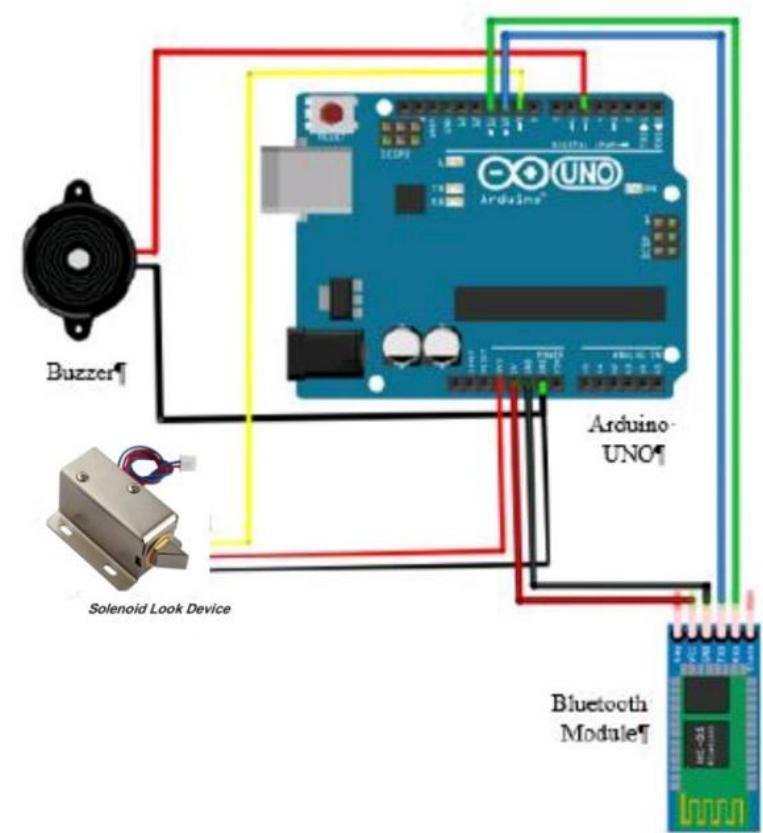

Figure 1. Hardware circuit connection of SCFDLS

requirements for hardware and software.

Table 1. H/W and S/W Requirement

\begin{tabular}{|l|l|}
\hline Hardware & Software \\
\hline 1) Arduino Port & Android Application \\
\hline 2) Bluetooth Module(HC05) & Kodular.Io (frame work) \\
\hline 3) Solenoid look device & Embedded C \\
\hline 4) Buzzer & Google Firebase \\
\hline
\end{tabular}




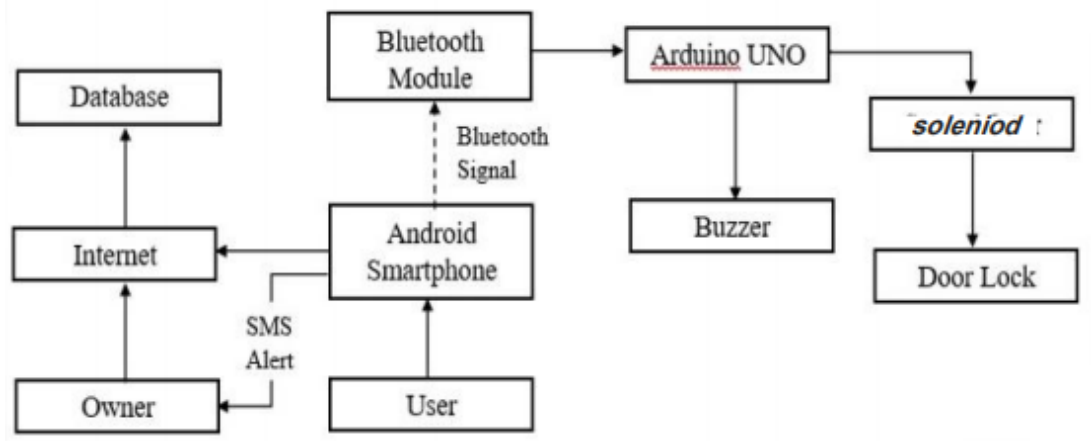

Figure 2. Block diagram of the proposed system

\subsection{Implementation of the proposed system}

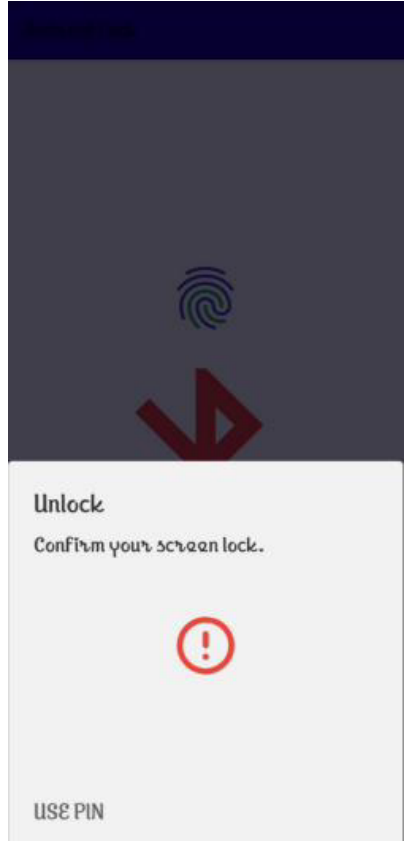

(a)

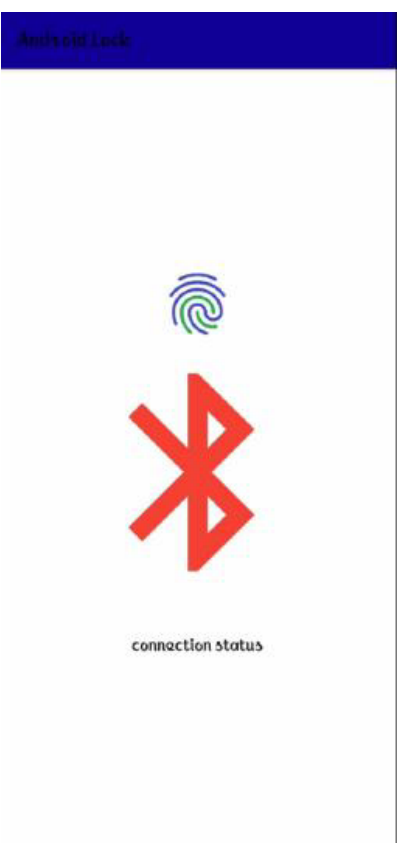

(b)

Figure 3. App Open and Unlock

Hardware circuit connection of the proposed system is shown in figure. Shows the square graph of the mechanized the entryway security framework utilizing the Android application. The circuit associations of the proposed the framework are shown in Figure 1. Interface the board to the PC utilizing the USB link. The USB the affiliation with the PC is vital to software the board, and moreover to the pressure it up. The UNO board therefore is managed from both the USB or the outer pressure supply. In the IDE (Integrated Development Environment) of Arduino, under the tool's menu, pick out the board 
as Arduino UNO and the port as Arduino UNO (COM3). The Arduino cartoon written in Embedded is uploaded to the Arduino UNO from the IDE... Next, the Android utility is hooked up at the cellular based smartphone and the Bluetooth gadgets is paired (join the smartphone and HC-05). Once the Bluetooth module is paired with the smartphone, the person can begin the usage of the app.

Figure 3 Open the android application and the unlock the confirm screen lock click on the fingerprint Connection is the success full then displaying the connection status.

Figure 4 Then click on Bluetooth Symbol Select Door Lock HC-05 from the listing of paired Bluetooth gadgets that seem at the display The consumer credentials are saved in the database. The proprietor can replace or has to alter the consumer credentials in the fire base database and registers the app with the database. After getting into the statistics click on at the login. The entered statistics is tested with the aid of using retrieving the consumer credentials from the database over the internet.

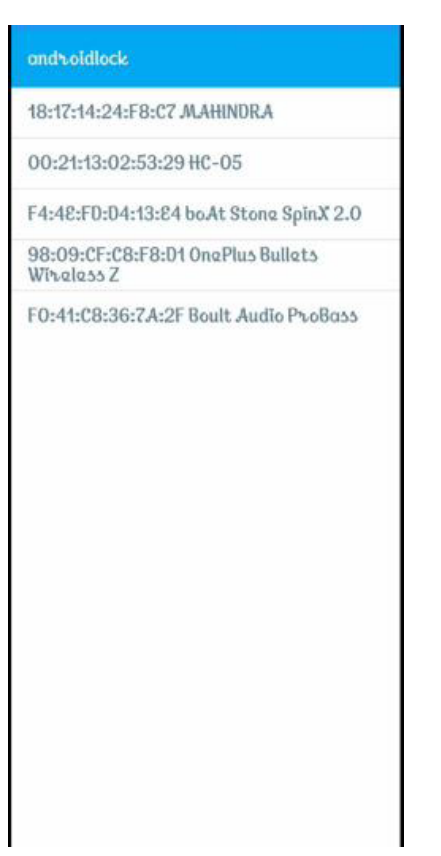

(a)

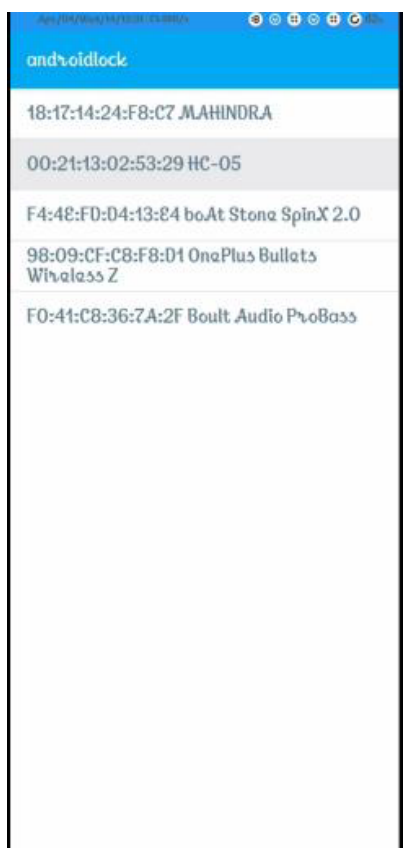

(b)

Figure 4. Click on Bluetooth and HC-05

The verification may be monitored through shooting the requests, and responses which are despatched and obtained through the software the usage of the Wireshark software, the community protocol examine which captures community packets and presentations it as human-readable. If the credentials (the fingerprint) are correct, the buttons to manipulate the door lock. The LOCK and the UNLOCK buttons may be enabled for the person at the screen.

Figure 5 if UNLOCK button is clicked and enabled by the user, if finger print authentication is succeeded, a $12 \mathrm{~V}$ current will be sent to a Bluetooth module(HC05). Then the current will be passed through a Buzzer and to an Arduino UNO and finally it reaches the Solenoid Lock Device. At last, the circuit checks for the current and the lock open. 


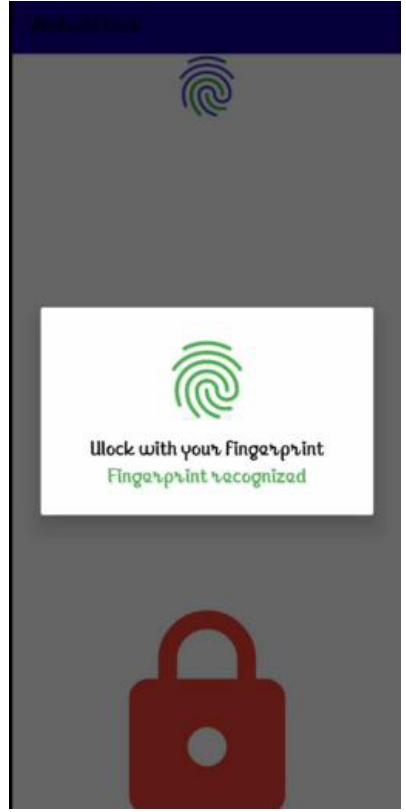

Figure 5. Click UNLock and Successful Authentication

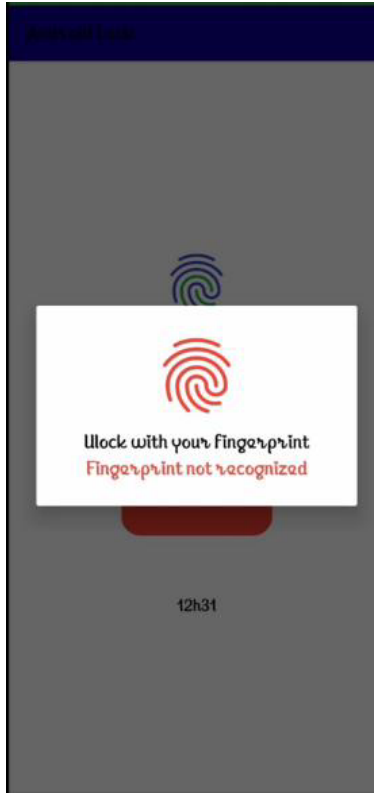

Figure 6. Click on Lock and Failed Authentication

Figure 6 Likewise If the LOCK button is enabled or clicked by the user, If the finger print authentication is Failed, the $12 \mathrm{v}$ current will be sent to the Bluetooth module(HC05). Then the current will be passed through Buzzer and to Arduino UNO and finally it reaches the Solenoid Lock Device. At last, the circuit checks for the current, and the lock Close. If the fingerprint isn't matched the person will now no longer be enabled with the buttons to govern the door lock and a sign could be despatched to the buzzer that makes it ring in conjunction with which an alert SMS could be despatched from the person's smartphone range to the owner's smartphone. A caution notification additionally pops up at the display to the person.

\subsection{System Safety}

Rather than the use of the bodily key, this device makes use of the sign this is introduced digitally thru Bluetooth from any telephone or different cell devices. The proposed the device has the specific fingerprint for every person maintained inside the database, which makes it strong within any of the robbery case or the safety breach of the cell device. If the person enters the incorrect person credentials, the device will generate the popup caution notification to suggest the invalid person credentials and could alert the neighbour with the buzzer ring and additionally intimate, the residence proprietor with the alert SMS. These capabilities decorate the overall protection of the device. 


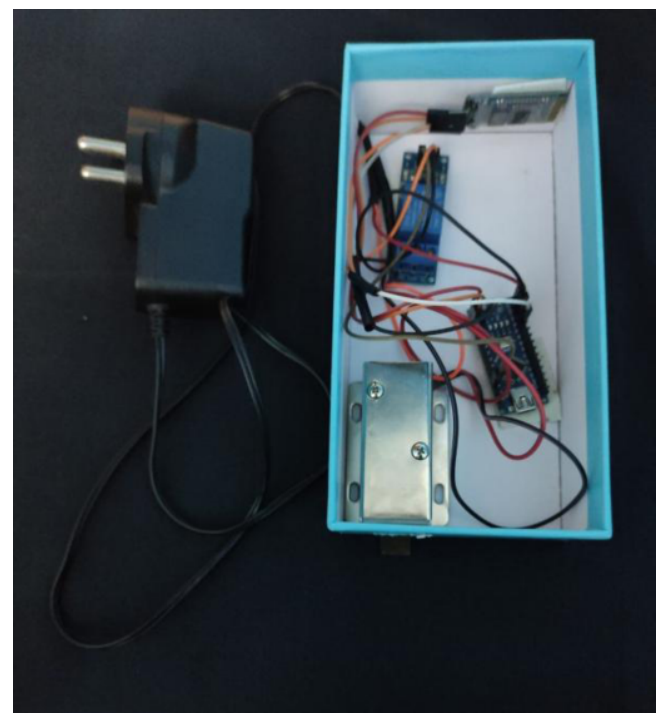

Figure 7. SCFDLS Prototype

\section{Conclusion}

In this paper, a clever domestic automation gadget particularly a virtual door lock is proposed to offer security. The gadget doesn't require any bodily keys to fasten or free up the door, instead, an android utility is established on clever devices, and credentials are used for the same. The consumer credentials are confirmed with the aid of using the database. If invalid credentials are furnished within the utility, a buzzer alarm is produced with an SMS alert to the residence proprietor together with a popup caution notification to the consumer. This complements the safety of the proposed method. It is a versatile gadget that is easy to put in at a low fee without any overhead like drafting and creation works.

\section{References}

[1] Sriskanthan N, Tan F, Karande A. Bluetooth based home automation system. Microprocessors and microsystems. 2002 Aug 10;26(6):281-9.

[2] Magar S, Saste V, Lahane A, Konde S, Madne S. Smart home automation by GSM using android application. In2017 International conference on information communication and embedded systems (ICICES) 2017 Feb 23 (pp. 1-4). IEEE.

[3] Toschi GM, Campos LB, Cugnasca CE. Home automation networks: A survey. Computer Standards \& Interfaces. 2017 Feb 1;50:42-54.

[4] Al-Ali A, Qasaimeh M, Al-Mardini M, Radder S, Zualkernan IA. ZigBee-based irrigation system for home gardens. In2015 International Conference on Communications, Signal Processing, and their Applications (ICCSPA'15) 2015 Feb 17 (pp. 1-5). IEEE.

[5] Anand J, Flora TA, Philip AS. Finger-vein based biometric security system. International Journal of Research in Engineering and Technology eISSN. 2013 Dec:197-200.

[6] Savita KS, Razip MM, Mehat M, Muniandy M. Bluetooth drawer (BD) lock system for student's residential. In 2017 IEEE Conference on e-Learning, e-Management and e-Services (IC3e) 2017 Nov 16 (pp. 18-23). IEEE. 
[7] Shanthini M, Vidya G, Arun R. IoT Enhanced Smart Door Locking System. In 2020 Third International Conference on Smart Systems and Inventive Technology (ICSSIT) 2020 Aug 20 (pp. 92-96). IEEE.

[8] Al Rasyid MU, Saputra FA, Prasetiyo A. I-on smart controller: Portable smart home solution based on arduino and raspberry pi. In2018 International Conference on Applied Science and Technology (ICAST) 2018 Oct 26 (pp. 161-164). IEEE.

[9] Cekada TL. Training a multigenerational workforce: Understanding key needs \& learning styles. Professional Safety. 2012 Mar 1;57(03):40-4.

[10] Reilly P. Understanding and Teaching Generation Y. InEnglish teaching forum 2012 (Vol. 50, No. 1, pp. 2-11). US Department of State. Bureau of Educational and Cultural Affairs, Office of English Language Programs, SA-5, 2200 C Street NW 4th Floor, Washington, DC 20037.

[11] Gurek A, Gur C, Gurakin C, Akdeniz M, Metin SK, Korkmaz I. An Android based home automation system. In 2013 High Capacity Optical Networks and Emerging/Enabling Technologies 2013 Dec 11 (pp. 121-125). IEEE.

[12] Pawar P, Avhad P, Nalawade H, Gofane D, Kadam S. Android Supported Smart Home Automation for Indoor and Outdoor Environments. International Journal of Computer Applications.2016;2016(6):1922.

[13] Takayama L, Pantofaru C, Robson D, Soto B, Barry M. Making technology homey: finding sources of satisfaction and meaning in home automation. InProceedings of the 2012 ACM conference on ubiquitous computing 2012 Sep 5 (pp. 511-520).

[14] Anand J, Flora A. TG: Emergency traffic management for ambulance using wireless communication. IPASJ Int. J. Electron. Commun.(IIJEC). 2014;2(7):1-4.

[15] Anand J, Perinbam JR. Automatic Irrigation System using Fuzzy Logic. AE International Journal of Multidisciplinary Research. 2014 Aug;2(8):1-9.

[16] Ganesh S, Prem Kumar R. Implementation of Secure Door Automation Systems using Infrared Sensors. International Journal of Trendy Research in Engineering and Technology. 2020 Oct;4(6):1-5.

[17] Vijayakumar P, Nandini N, Sai Ganesh N, Lawand RS, Bharadwaja AV, Tamizhselvan C, Aukush YK. Smart Calendar Device for Differently Abled Person. International Journal of Innovative Technology and Exploring Engineering. 2019 May;8(7):1410-4.

[18] Ajay H, Rao AR, Balavanan M, Lalit R. A Novel Cardiac Arrest Alerting System using IoT. International Journal of Science Technology \& Engineering. 2017;3(10):78-83.

[19] Anand J, Dhanalakshmi M, Raja Paul Perinpam J. Smart Indication System for Spinal Cord Stress Detection. International Journal of Recent Technology and Engineering. 2019 Sep;8(3):6164-8.

[20] Niranjana S, Hareshaa SK, Irene ZB, Anand J. Smart Monitoring System for Asthma Patients. International Journal of Electronics and Communication Engineering. 2020 May;7(5):5-9. 